\title{
Distinguishing four components underlying physical activity: a new approach to using physical activity questionnaire data in old age
}

\author{
Lisanne M Verweij*1, Natasja M van Schoor ${ }^{1}$, Joost Dekker ${ }^{1,2}$ and Marjolein Visser 1,3
}

\begin{abstract}
Background: It is evident that physical activity has many benefits, but it often remains unclear which types of activity are optimal for health and functioning in old age. The aim of this methodological study was to propose a method for distinguishing four components underlying self reported physical activity of older adults: intensity, muscle strength, turning actions and mechanical strain.

Methods: Physical activity was assessed by the validated LAPAQ questionnaire among 1699 older adults of the Longitudinal Aging Study Amsterdam. Based on expert consultation and literature review, the four component scores for several individual daily and sports activities were developed. Factor analysis was performed to confirm whether the developed components indeed measured different constructs of physical activity.

Results: Based on the factor analyses, three components were distinguished: 1. intensity and muscle strength loaded on the same factor, 2. mechanical strain and 3. turning actions. Analyses in gender, age and activity level subgroups consistently distinguished three factors.

Conclusion: Future research using these components may contribute to our understanding of how specific daily and sports activities may have a different influence on health and physical functioning in old age.
\end{abstract}

\section{Background}

It is well established that physical activity is essential in healthy aging. With aging, fitness levels decrease and functional impairments and chronic diseases often arise [1]. These health declines may lead to functional limitations and can result in an increased risk of falling and a diminished independence among older adults [2]. By engaging in physical activity, these age related declines can be reduced and even improvement of neuromuscular and physical function, quality of life and disease risk in older adults may occur [3-13].

Recently, new physical activity recommendations for older adults were published based on the latest evidence and expert consensus [1]. It was stated that physical activity of older adults should emphasize moderate-intensity aerobic activity, muscle strengthening activities and possibly weight bearing activities. However, it remains

* Correspondence: I.verweij@vumc.nl

1 EMGO Institute for Health and Care Research, VU University Medical Center, Amsterdam, the Netherlands

Full list of author information is available at the end of the article unclear what type of activities are optimal for improving health and preventing disease in old age [14]. The following example illustrates the complex influence of physical activity on health. During tennis, the high weight bearing forces may be beneficial for maintaining bone density in postmenopausal women [15] but may increase the risk for osteoarthritis [16]. Additionally, the many turning actions during tennis may increase the risk of falling [17], but the high intensity and muscle strength involved may prevent injury and reduce the risk of cardio-vascular disease $[18,19]$. This example illustrates that a single activity consists of different components, which all may have different relationships with a health outcome.

The aim of the present methodological study is to suggest a new way of evaluating physical activity of older adults by proposing different components underlying self-reported physical activity, namely intensity, muscle strength, turning actions and mechanical strain. The study is based on data from a physical activity questionnaire, as currently available objective methods to assess 
physical activity level do not provide information on the type of the activities performed. In distinguishing between these four underlying components new insights in the relationship between physical activities and prevalent and incident disease and functioning may be gained, from which a more tailored physical activity advice for older persons can be developed in future studies.

\section{Methods \\ Subjects}

Data were used from the Longitudinal Aging Study Amsterdam (LASA), an ongoing study in a representative sample of 3107 older persons, aged 55-85 years. Respondents were recruited from three areas in the Netherlands and were stratified for age, gender and 5-year mortality at baseline (1992/1993). Measurements and interviews on social, cognitive, psychological and physical functioning are repeated every three years [20]. For the present study, data were used from respondents who completed the third data collection cycle of LASA (1998/1999, $\mathrm{n}=$ 1874). Participants were excluded when they were bedridden, wheelchair dependent or had a missing mobility status $(\mathrm{n}=149)$ and when they performed no daily or sport activities $(n=26)$, resulting in 1699 respondents for analyses. The LASA study was approved by the Ethical Review Board of the VU University Medical Center. All respondents signed informed consent on entering the study.

\section{Measurements}

Daily and sport activities were assessed using the LASA Physical Activity Questionnaire (LAPAQ), which provides a valid and reliable measure of physical activity in older adults [21]. Frequency and duration of activities over the past 2 weeks were asked for walking, bicycling, light and heavy household work and a maximum of two sports.

The variables gender, age, education and body mass index were used to describe the study sample. Education was divided into three categories; low (elementary school or less), medium (primary and secondary education) and high education (college and university). Body mass index (BMI) was calculated using measured weight and height and was expressed in $\mathrm{kg} / \mathrm{m}^{2}$.

\section{Development of component scores}

Based on literature review and expert consultation, every LAPAQ activity was given a score for the intensity, the required muscle strength, the mechanical strain and the turning actions component. All experts (three occupational therapists and three professors in the area of biomechanics, allied health care and healthy aging) individually decided on the scores. The proposed scores were discussed by the three professors to reach consen- sus. Scores and rationale were provided by other studies for the intensity, mechanical strain and turning action component scores [22-24]. Because no score was available for the muscle strength component we constructed and validated this component for the purpose of this study.

\section{Intensity}

The intensity of physical activities was expressed in metabolic equivalents (MET) as described in the compendium of Ainsworth, a reliable classification system [25]. The compendium contains a coding scheme to classify activities according to their intensity, with one MET being equivalent to $1 \mathrm{kcal}^{*} \mathrm{~kg}$ body weight*hour. In the present study, MET scores were adapted for older persons to adjust for the fact that older persons generally perform these activities at a lower intensity [26].

\section{Mechanical strain}

The mechanical strain scores represent the loading of the bone and were derived from ground reaction forces (GRF) expressed in multiples of body weight [27]. A score of 1 was given to activities with GRF values up to one time the body weight (non weight bearing activities and standing activities). Score 2 represented those activities with GRF values between one and two times body weight (weight bearing activities). Score 3 described those activities with GRF values between two and four times body weight (activities including explosive actions such as sprinting and running) and score 4 indicated physical activities with GRF greater than four times body weight (activities including jumping). This score has a good face validity [23].

\section{Turning actions}

In the original mechanical strain classification by Groothausen et al. turning actions were incorporated in the mechanical strain score 3 (activities including sprinting and running) [24]. However, as Besier et al. noted, turning actions are also present in jumping, squatting and weight bearing activities [28]. Therefore, the turning actions component was separated from the mechanical strain component. Turning actions were defined as activities in which transversal rotations of the lower extremities were present. The turning action scores ranged from 1 to 3 , with the highest score representing activities associated with numerous turning actions, such as dancing and tennis, and the lowest score indicating few to no turning actions during the activities, such as walking and bicycling.

\section{Muscle strength}

The muscle strength component indicates the amount of required lower body muscle strength to perform an activity. Literature review did not provide information on strength required during specific activities. Therefore, the muscle strength associated with specific activities was based on expert consultation. This resulted in the follow- 
ing scores: score 4 contained activities involving jumping and squatting actions; score 3 represented activities which include running or cycling; score 2 included activities related to walking; score 1 included standing and sitting activities. The validity of this score was examined by assuming that those who frequently perform activities requiring a high muscle strength would have a higher quadriceps and hand grip strength as assessed by dynamometry. Quadriceps muscle strength is representative for lower extremity strength which is extremely important for activities of daily living [2], while handgrip strength is a more general measure for overall muscle strength [29].

We used data from a sub sample of 418 respondents of LASA (1999/2000) with quadriceps strength and hand grip strength measurements [30]. Quadriceps muscle strength was measured as the maximal leg extension strength, using a hand held dynamometer (MicroFET, Hoggan Health Industries Inc., Draper, UT) according to the method of Hsieh and Philips [31]. Strength measurements were performed on both legs at least four times, with a maximum of seven times. The maximum strength measurements of both legs were added and divided by two. Handgrip strength was measured with a straingauged dynamometer (Takei TKK 5001; Takei Scientific Instruments, Tokyo, Japan). Two maximum force measurements were conducted with each hand. Again, the maximum strength measurements of both hands were summed and divided by two.

\section{Mean component score per person}

Based on the individual activities performed by a person and the component scores for those activities, a mean score for each component was calculated for that person [23]. For example, a respondent who performed light household activities (2.5 MET) and played tennis (6.0 MET) would receive a mean intensity component score of 4.3 MET.

\section{Statistical analyses}

Analyses were performed using SPSS, version 14.0 (Chicago; SPSS Inc). P values less than 0.05 were considered statistically significant. First, the validity of the developed muscle strength component score was assessed in the subsample by concurrent and construct validity. A Spearman's correlation coefficient of at least 0.30 between the developed muscle strength component score and actual quadriceps and handgrip strength measurements would indicate medium concurrent validity [32]. The correlations of the actual strength measurements with the intensity, mechanical strain and turning action component scores would have to be lower to indicate construct validity of the muscle strength component.

Secondly, we assessed whether the four developed component scores indeed measured different constructs of physical activity. A principal component analysis with
Varimax rotation was performed in the total study sample. In determining the number of factors which can be distinguished, the eigenvalues, the explained variance, intercorrelations and the scree test were visually inspected. Although an eigenvalue larger than 1 is the most common used cut-off point in factor analyses, it is strongly recommended not to use this as the sole cut-off criteria for determining the number of factors [33]. Because only four variables were investigated the Joliffe criterion was used, excluding all components with eigenvalues under 0.7 [34]. The total explained variance was expected to be over $80 \%$ and the correlation matrix was expected to show correlations under 0.70 . The scree test was inspected for breaks in the distribution [35]. To examine the robustness of our approach, the factor analyses were repeated for the following subgroups: men and women, young old (aged $<73 \mathrm{y}$ ) and old old (aged $\geq 73 \mathrm{y}$ ), and inactive $(<139$ minutes per day) and active respondents ( $\geq 139$ minutes per day) using the sample median as the cut point.

\section{Results}

Descriptive characteristics of the study samples are shown in Table 1. Overall, the average age was 78 years in the sub sample and 73 years in the total sample, and respondents in both samples were physically active for about two and a half hours a day. Excluded respondents in the total samples were older, had a lower muscle strength, education level and BMI, and were less active (p $<0.05$ ).

The final component scores per activity are presented in Table 2. The mean component scores (standard deviation) for the total study sample were $3.60(0.46)$ for intensity, $1.49(0.21)$ for mechanical strain, $1.55(0.21)$ for turning actions and 2.54 (0.35) for muscle strength.

Concurrent and construct validity of the muscle strength component score were investigated using measured quadriceps and handgrip strength (Tables 3 and 4). Positive correlations between the strength component score and measured quadriceps and handgrip strength were found $(r=0.36$ and $r=0.37$ respectively) indicating medium concurrent validity. However, the intensity component score correlated equally high with measured quadriceps strength and handgrip strength $(r=0.33$ and $r$ $=0.32$ respectively) indicating poor construct validity. $\mathrm{A}$ strong correlation was found between the muscle strength component score and the intensity component score $(r=0.67)$, but the correlation with mechanical strain $(r=0.02)$ and with turning actions $(r=-0.25)$ was low.

The factor analyses identified three factors with a total explained variance of 96\%: 1 . intensity and muscle strength loaded on the same factor, 2. mechanical strain and 3. turning actions (Table 5). Three factors could also be identified when viewing the scree plot. The correlation 
Table 1: Respondent characteristics of the study sample and the validation sub sample.

\begin{tabular}{lcc}
\hline Characteristics & Sub sample (N = 418) & Total sample (N= 1699) \\
\hline Age (years, SD) & $78(6.1)$ & $73(8.0)$ \\
Gender (\% female) & 54 & 54 \\
Education (\%) & 37 & 38 \\
$\quad$ Primary & 53 & 50 \\
$\quad$ Secondary & 10 & 13 \\
$\quad$ College/University & $27.2(4.1)$ & $27.5(4.2)$ \\
BMI (kg/m², SD) & $146(40)$ & - \\
Quadriceps strength (N, SD) & $27.9(10.2)$ & $25.6(10.6)$ \\
Handgrip strength (kgf, SD) & $155(117)$ & $157(102)$ \\
Physical activity (min/day, SD)
\end{tabular}

Table 2: The four developed physical activity component scores for the individual activities included in the LASA Physical Activity Questionnaire (LAPAQ).

\begin{tabular}{|c|c|c|c|c|}
\hline LAPAQ Activity & $\begin{array}{l}\text { Intensity component } \\
\text { score }\end{array}$ & $\begin{array}{l}\text { Mechanical strain } \\
\text { component score }\end{array}$ & $\begin{array}{l}\text { Turning actions } \\
\text { component score }\end{array}$ & $\begin{array}{l}\text { Strength component } \\
\text { score }\end{array}$ \\
\hline \multicolumn{5}{|l|}{ General: } \\
\hline Walking outdoors & 3.5 & 2 & 1 & 2 \\
\hline Bicycling & 4.5 & 1 & 1 & 3 \\
\hline Light household & 2.5 & 1 & 2 & 2 \\
\hline Heavy household & 4.5 & 2 & 2 & 4 \\
\hline \multicolumn{5}{|l|}{ Sports: } \\
\hline 1. Distance walking & 4.0 & 2 & 1 & 3 \\
\hline 2. Distance cycling & 6.0 & 1 & 1 & 4 \\
\hline 3. Gym/Game & 4.0 & 2 & 2 & 2 \\
\hline 4. Home trainer & 4.0 & 1 & 1 & 2 \\
\hline 5. Swimming & 5.0 & 1 & 2 & 3 \\
\hline 6.(Folk) Dancing & 5.0 & 3 & 3 & 2 \\
\hline $\begin{array}{l}\text { 7. Bowling/Jeu de } \\
\text { Boules }\end{array}$ & 3.5 & 2 & 2 & 3 \\
\hline 8. Tennis/Badminton & 6.0 & 3 & 3 & 3 \\
\hline $\begin{array}{l}\text { 9. Jogging/Running/ } \\
\text { Speed walking }\end{array}$ & 6.0 & 3 & 1 & 3 \\
\hline 10. Rowing & 5.5 & 1 & 1 & 3 \\
\hline 11. Sailing & 3.0 & 1 & 1 & 2 \\
\hline 12. Billiards & 2.5 & 1 & 1 & 3 \\
\hline 13. Fishing & 3.0 & 1 & 1 & 1 \\
\hline $\begin{array}{l}\text { 14. Soccer/Basketball/ } \\
\text { Hockey }\end{array}$ & 6.0 & 4 & 3 & 4 \\
\hline 15. Volleyball/Baseball & 5.0 & 4 & 3 & 4 \\
\hline 16. Skiing & 6.0 & 2 & 3 & 4 \\
\hline 17. All other activities & 4.0 & 2 & 2 & 2 \\
\hline
\end{tabular}


Table 3: Spearman correlations coefficient between measured muscle strength and the four physical activity component scores in the sub sample.

\begin{tabular}{llc}
\hline & Measured quadriceps strength & Measured handgrip strength \\
\hline Muscle strength component & .36 & .37 \\
Intensity component & .33 & .32 \\
Mechanical strain component & .02 & .00 \\
Turning actions component & -.15 & -.29 \\
\hline
\end{tabular}

matrix showed correlations under 0.70 . In repeating the factor analyses within gender, age and activity level subgroups, the same three factors were consistently distinguished showing less than $10 \%$ change (data not shown). Results of additional factor analyses suggest that mean scores are indeed more important than sum and maximum scores (data not shown).

\section{Discussion}

The aim of this methodological study was to propose a new approach to use physical activity data of older persons obtained by questionnaire. Four underlying components of physical activity were distinguished based on literature and expert consultation, including intensity, muscle strength, mechanical strain and turning action components. Results from the factor analyses showed that the mechanical strain and turning actions components indeed were distinct factors, but intensity and muscle strength loaded onto a single factor. Therefore, three underlying components of physical activity could be distinguished. Using these components in future research may help our understanding of the association between physical activity and health in old age, which will ultimately lead to a more specific and tailored physical activity advice for older persons.

The intensity, mechanical strain and turning action component scores were based on previously developed scores which were slightly adapted [22,27]. The muscle strength component score was developed and validated against actual measurements of muscle strength. Although these concepts are clearly related, it should be kept in mind that the questionnaire asks what a person does while the strength measure reflects what a person is able to do. The results showed that a high strength component score was indeed correlated with higher values of quadriceps strength and hand grip strength. However, construct validity was limited because of the high correlation of the muscle strength component score as well as the intensity component score with measured muscle strength. This was confirmed by the results of the factor analysis, showing that the intensity component and the muscle strength component loaded on a single factor. Additional factor analyses in different subgroups of older adults consistently confirmed this.

To confirm whether the four proposed components indeed each represented a different aspect of physical activity, we performed a factor analysis. These results suggest that the intensity and muscle strength components as developed in this study measure the same underlying construct and that mechanical strain component and the turning actions component were to distinctive, additional factors. This implies that future analyses should contain either the muscle strength component or the intensity component, or a combined average score.

Some limitations of this study must be reported. Our main aim of this study was to propose a new conceptual use of physical activity questionnaire data. The generalizability of our findings to other physical activity questionnaires and to different populations is not known. Therefore, future studies are needed to validate our approach and underlying assumptions in other datasets using questionnaires that contain the same domains as the LAPAQ (walking, bicycling, household activities and sports) and to extend our results using questionnaires that include other domains. Second, the total amount of physical activity performed by the respondents, expressed in minutes per day, or the total time spend on each activity was not incorporated in each persons' component score. As our components are based on the nature of activities (which type of activities are similar in their component score) we feel it is more applicable to keep nature and duration separated, because scores are other-

Table 4: Intercorrelation coefficients between the four physical activity components score in the sub sample.

$\begin{array}{ccc}\text { Intensity } & \text { Mechanical strain } & \text { Turning actions component } \\ \text { component } & \text { component } & \end{array}$

\begin{tabular}{lccc} 
Muscle strength component & .67 & -.06 & -.24 \\
Intensity component & & .02 & -.25 \\
Mechanical strain component & & .31 \\
\hline
\end{tabular}


Table 5: Factor analysis based on the four physical activity component scores.

\begin{tabular}{|c|c|c|c|c|}
\hline & \multicolumn{4}{|c|}{ Factor } \\
\hline & 1 & 2 & 3 & 4 \\
\hline \multicolumn{5}{|l|}{ Item* } \\
\hline $\begin{array}{l}\text { Muscle strength } \\
\text { component }\end{array}$ & .96 & - & - & - \\
\hline Intensity component & .90 & - & - & - \\
\hline $\begin{array}{l}\text { Mechanical strain } \\
\text { component }\end{array}$ & - & .99 & - & - \\
\hline $\begin{array}{l}\text { Turning actions } \\
\text { component }\end{array}$ & - & - & .99 & - \\
\hline \multicolumn{5}{|l|}{ Value } \\
\hline Eigenvalue & 2.02 & 0.98 & 0.84 & 0.15 \\
\hline \% Variance Explained & 51 & 25 & 21 & 4 \\
\hline
\end{tabular}

* Only factor loadings $>0.4$ are shown.

wise more difficult to make, and to interpret. Nevertheless, when relating the component scores to health outcomes in future studies, adjustment for total activity level or activity duration should be made [36]. Third, in this type of studies it would also be of interest to investigate potential interaction between components. For example, it should be examined whether persons with a high mechanical strain component score could attenuate their risk for knee OA by having a high muscle strength component score. Moreover, both observational and intervention studies are needed to further elucidate the potential role of different types of physical activity in the development of knee OA to allow more specific physical activity advice for older persons. Fourth, future studies should ask all sports a person performs. Our physical activity scores may be underestimated as the physical activity questions were limited to the most usual daily activities and a maximum of the two most intensive sports activities. Finally, further research is needed to translate the current results to clinical practice. Although the LAPAQ can be completed in approximately six minutes and is easy to fill in $(0.5 \%$ of the respondents had missing values [21]), this is too long for the clinical setting. Seven similar questionnaires were investigated and were also found too long and complex for routine administration, because all questionnaires were developed for the research setting [37]. Thus, simple scoring lists including the most relevant types of activities should be developed and easy interpretation of the results by the clinician is needed to allow for good feasibility and interpretation in a clinical setting.

\section{Conclusion}

The results of this study show that different components underlying physical activity in older adults can be identi- fied. The results suggest that at least three components may exist including a mechanical strain component, a turning actions component and a combined intensity/ muscle strength component. As recent studies by our group [38,39] and others [40-44] show, these components may differ in their relation with health outcomes.

The use of these components in future studies may further improve our understanding of the mechanisms by which physical activities influence prevalent and incident disease in old age, ultimately enabling the development of specific and tailored physical activity advice for older adults.

\section{Competing interests}

The authors declare that they have no competing interests.

\section{Authors' contributions}

LV and MV had a role in the study concept and design. MV and NVS provided acquisition of subjects and data. LV, NvS, JD, MV contributed to the analysis and interpretation of data and preparation of the manuscript. All authors read and approved the final manuscript.

\section{Acknowledgements}

The Longitudinal Aging Study Amsterdam is financially supported by the Dutch Ministry of Public Health, Welfare and Sports. This study is funded by the Royal Dutch Society for Physical Therapy (KNGF).

\section{Author Details}

1EMGO Institute for Health and Care Research, VU University Medical Center, Amsterdam, the Netherlands, 2Department of Rehabilitation Medicine, VU University Medical Center, Amsterdam, the Netherlands and ${ }^{3}$ Institute of Health Sciences, Faculty of Earth and Life Sciences, VU University, Amsterdam, the Netherlands

Received: 21 October 2009 Accepted: 3 May 2010

Published: 3 May 2010

References

1. Nelson ME, Rejeski WJ, Blair SN, Duncan PW, Judge JO, King AC, et al: Physical activity and public health in older adults: recommendation from the American College of Sports Medicine and the American Heart Association. Med Sci Sports Exerc 2007, 39:1435-1445. 
2. Hurley MV: The role of muscle weakness in the pathogenesis of osteoarthritis. Rheum Dis Clin North Am 1999, 25:283-98.

3. Spirduso WW, Cronin DL: Exercise dose-response effects on quality of life and independent living in older adults. Med Sci Sports Exerc 2001, 33:S598-S608.

4. American College of Sports Medicine Position Stand. Exercise and physical activity for older adults. Med Sci Sports Exerc 1998, 30:992-1008.

5. Blair SN, Kohl HW, Gordon NF, Paffenbarger RS Jr: How much physical activity is good for health? Annu Rev Public Health 1992, 13:99-126.

6. Blair SN, Connelly JC: How much physical activity should we do? The case for moderate amounts and intensities of physical activity. Res $Q$ Exerc Sport 1996, 67:193-205.

7. Cress ME, Buchner DM, Prohaska T, Rimmer J, Brown M, Macera C, et al.: Best practices for physical activity programs and behavior counseling in older adult populations. J Aging Phys Act 2005, 13:61-74

8. King AC, Rejeski WJ, Buchner DM: Physical activity interventions targeting older adults. A critical review and recommendations. Am J Prev Med 1998, 15:316-333.

9. Hui EK, Rubenstein LZ: Promoting physical activity and exercise in older adults. J Am Med Dir Assoc 2006, 7:310-314.

10. Visser M, Pluijm SM, Stel VS, Bosscher RJ, Deeg DJ: Physical activity as a determinant of change in mobility performance: the Longitudinal Aging Study Amsterdam. J Am Geriatr Soc 2002, 50:1774-1781.

11. Kostka T, Bonnefoy M, Arsac LM, Berthouze SE, Belli A, Lacour JR: Habitual physical activity and peak anaerobic power in elderly women. Eur J Appl Physiol Occup Physiol 1997, 76:81-87.

12. Rantanen $T$, Era P, Heikkinen E: Physical activity and the changes in maximal isometric strength in men and women from the age of 75 to 80 years. J Am Geriatr Soc 1997, 45:1439-1445.

13. Visser M, Simonsick EM, Colbert LH, Brach J, Rubin SM, Kritchevsky SB, et al.: Type and intensity of activity and risk of mobility limitation: the mediating role of muscle parameters. J Am Geriatr Soc 2005, 53:762-770.

14. Vincent KR, Braith RW, Feldman RA, Magyari PM, Cutler RB, Persin SA, et al:: Resistance exercise and physical performance in adults aged 60 to 83 . J Am Geriatr Soc 2002, 50:1 100-1107.

15. Shea B, Bonaiuti D, lovine R, Negrini S, Robinson V, Kemper HC, et al: Cochrane Review on exercise for preventing and treating osteoporosis in postmenopausal women. Eura Medicophys 2004, 40:199-209.

16. Spector TD, Harris PA, Hart DJ, Cicuttini FM, Nandra D, Etherington J, et al: Risk of osteoarthritis associated with long-term weight-bearing sports: a radiologic survey of the hips and knees in female ex-athletes and population controls. Arthritis Rheum 1996, 39:988-995.

17. Topper AK, Maki BE, Holliday PJ: Are activity-based assessments of balance and gait in the elderly predictive of risk of falling and/or type of fall? J Am Geriatr Soc 1993, 41:479-487.

18. Leach RE, Abramowitz A: The senior tennis player. Clin Sports Med 1991 10:283-290

19. Pluim BM, Staal JB, Marks BL, Miller S, Miley D: Health benefits of tennis. Br J Sports Med 2007, 41:760-768

20. Deeg DJ, van Tilburg TT, Smit JH, de Leeuw ED: Attrition in the Longitudinal Aging Study Amsterdam. The effect of differential inclusion in side studies. J Clin Epidemio/ 2002, 55:319-328.

21. Stel VS, Smit JH, Pluijm SM, Visser M, Deeg DJ, Lips P: Comparison of the LASA Physical Activity Questionnaire with a 7-day diary and pedometer. J Clin Epidemiol 2004, 57:252-258

22. Ainsworth BE, Haskell WL, Leon AS, Jacobs DR Jr, Montoye HJ, Sallis JF, et al: Compendium of physical activities: classification of energy costs of human physical activities. Med Sci Sports Exerc 1993, 25:71-80.

23. Kemper HC, Bakker I, Twisk JW, van Mechelen MW: Validation of a physical activity questionnaire to measure the effect of mechanical strain on bone mass. Bone 2002, 30:799-804.

24. Groothausen J, Siemer H, Kemper HC, Twisk JW, Welten DC: Influence of peak strain on lumbar bone mineral density: an analysis of 15 -year physical activity in young males and females. Pediatric Exercise Science 1997, 9:159-173.

25. Wilcox S, Irwin ML, Addy C, Stolarczyk L, Ainsworth BE, Whitt M, et al. Agreement between participant-rated and compendium-coded intensity of daily activities in a triethnic sample of women ages 40 years and older. Ann Behav Med 2001, 23:253-262.

26. Jones $L M$, Waters $D L$, Legge $M$ : Walking speed at self-selected exercise pace is lower but energy cost higher in older versus younger women. $J$ Phys Act Health 2009, 6:327-332.
27. Kemper HC, Twisk JW, van MW, Post GB, Roos JC, Lips P: A fifteen-year longitudinal study in young adults on the relation of physical activity and fitness with the development of the bone mass: The Amsterdam Growth And Health Longitudinal Study. Bone 2000, 27:847-853.

28. Besier TF, Lloyd DG, Cochrane JL, Ackland TR: External loading of the knee joint during running and cutting maneuvers. Med Sci Sports Exerc 2001, 33:1168-1175.

29. Rantanen T, Era P, Heikkinen E: Maximal isometric strength and mobility among 75-year-old men and women. Age Ageing 1994, 23:132-137.

30. Stel VS, Smit JH, Pluijm SM, Lips P: Balance and mobility performance as treatable risk factors for recurrent falling in older persons. J Clin Epidemiol 2003, 56:659-668.

31. Hsieh CY, Phillips RB: Reliability of manual muscle testing with a computerized dynamometer. J Manipulative Physiol Ther 1990, 13:72-82.

32. Cohen J, Cohen P, West SG, Aiken LS: Applied multiple regression/ correlation analysis for the behavioral sciences 3rd edition. Hillsdale, NJ: Lawrence Erlbaum Associates; 2003.

33. Lance CE, Butts MM, Michels LC: The sources of four commonly reported cutoff criteria: what did they really say? Organizational Research Methods 2006, 9:202-220.

34. Joliffe IT, Morgan BJ: Principal component analysis and exploratory factor analysis. Stat Methods Med Res 1992, 1:69-95.

35. Streiner DL: Figuring out factors: the use and misuse of factor analysis. Can J Psychiatry 1994, 39:135-140.

36. King AC, Rejeski WJ, Buchner DM: Physical activity interventions targeting older adults. A critical review and recommendations. Am J Prev Med 1998, 15:316-333.

37. Lamb SE, Jorstad-Stein EC, Hauer K, Becker C: Development of a common outcome data set for fall injury prevention trials: the Prevention of Falls Network Europe consensus. J Am Geriatr Soc 2005, 53:1618-1622.

38. Verweij LM, van Schoor NM, Deeg DJ, Dekker J, Visser M: Physical activity and incident clinical knee osteoarthritis in older adults. Arthritis Rheum 2009, 61:152-157.

39. Peeters GGME, Verweij LM, Schoor NMv, Pijnappels M, Pluijm SM, Visser M, et al:: Which types of activities are associated with risk of recurrent falling in older persons? Journal of Gerontology: Medical Sciences 2010 in press.

40. Vignon E, Valat JP, Rossignol M, Avouac B, Rozenberg S, Thoumie P, et al: Osteoarthritis of the knee and hip and activity: a systematic international review and synthesis (OASIS). Joint Bone Spine 2006 73:442-455

41. Haapanen-Niemi N, Miilunpalo S, Pasanen M, Vuori I, Oja P, Malmberg J: Body mass index, physical inactivity and low level of physical fitness as determinants of all-cause and cardiovascular disease mortality--16 y follow-up of middle-aged and elderly men and women. Int J Obes Relat Metab Disord 2000, 24:1465-1474.

42. Meinhart-Shibata P, Kramer M, shton-Miller JA, Persad C: Kinematic analyses of the 180 degrees standing turn: effects of age on strategies adopted by healthy young and older women. Gait Posture 2005, 22:119-125.

43. Colby S, Francisco A, Yu B, Kirkendall D, Finch M, Garrett W Jr: Electromyographic and kinematic analysis of cutting maneuvers. Implications for anterior cruciate ligament injury. Am J Sports Med 2000, 28:234-240

44. Liu-Ambrose T, Eng JJ, Khan KM, Carter ND, McKay HA: Older women with osteoporosis have increased postural sway and weaker quadriceps strength than counterparts with normal bone mass: overlooked determinants of fracture risk? J Gerontol A Biol Sci Med Sci 2003, 58:M862-M866.

\section{Pre-publication history}

The pre-publication history for this paper can be accessed here: http://www.biomedcentral.com/1471-2318/10/20/prepub

doi: $10.1186 / 1471-2318-10-20$

Cite this article as: Verweij et al., Distinguishing four components underlying physical activity: a new approach to using physical activity questionnaire data in old age BMC Geriatrics 2010, 10:20 